\title{
Predictors of limitations of physical activities of daily living among geriatric Nigerians with musculoskeletal disorders in under-resourced environment of a primary care clinic of a tertiary hospital in Eastern Nigeria
}

\author{
Gabriel Uche Pascal Iloh", ", Nnadozie Paul Obiegbu ${ }^{2}$, Abali Chuku , \\ Augustin Obiora Ikwudinma ${ }^{4}$ \\ ${ }^{1}$ Department of Family Medicine, Federal Medical Centre, Umuahia, Abia state, Nigeria \\ ${ }^{2}$ Ministry of Health, Awka, Anambra State, Nigeria and Trainer in Family Medicine Residency program, Department of Family Medicine, \\ Federal Medical Centre, Umuahia, Nigeria \\ ${ }^{3}$ Department of Ophthalmology Federal Medical Centre, Umuahia, Abia state, Nigeria \\ ${ }^{4}$ Department of Family Medicine, Federal Teaching Hospital Abakiliki, Nigeria
}

\section{Email address:}

ilohgup2009@yahoo.com(G. U. P. Iloh)

\section{To cite this article:}

Gabriel Uche Pascal Iloh, Nnadozie Paul Obiegbu, Abali Chuku, Augustin Obiora Ikwudinma. Predictors of Limitations of Physical Activities of Daily Living among Geriatric Nigerians with Musculoskeletal Disorders in Under-Resourced Environment of a Primary Care Clinic of a Tertiary Hospital in Eastern Nigeria. European Journal of Preventive Medicine. Vol. 1, No. 2, 2013, pp. 37-45. doi: $10.11648 /$ j.ejpm.20130102.11

\begin{abstract}
Background: Musculoskeletal disorders (MSDs) can have detrimental impact on physical activities of daily living (PADLs) of geriatric Nigerians and can trigger other chronic medical conditions. The virility of Nigerian elderly population therefore depends largely on their PADLs which are often challenged by MSDs. Aim: The study was designed to determine the predictors of limitations of physical activities of daily living among geriatric Nigerians with musculoskeletal disorders in under-resourced environment of a primary care clinic of a tertiary hospital in Eastern Nigeria. Materials and Methods: A cross-sectional study carried out on 894 geriatric patients who were screened for MSDs, 130 of them had diagnoses of MSDs and 116 who had limitations of their PADLs were studied for predictor variables. Data was collected using a pretested, structured and interviewer administered questionnaire. The PADL was scored on a four points Likert scale and assessed in the previous one month. Patients who scored 0 had no affectation of PADLs while those who scored 1-3 were variably affected. Results: The prevalence of MSDs was $14.5 \%$. One hundred and sixteen (89.2\%) out of 130 patients had their PADLs affected. Limitations of PADLs was significantly associated with age $\geq 75$ years $(\mathrm{p}=0.022)$ and urban residence $(\mathrm{p}=0.003)$. The most significant predictor of limitations of PADLs was urban residence $(\mathrm{p}=0.010$, $\mathrm{OR}=2.516(1.34$ - 5.02). The geriatric patients with MSDs in urban residence were two and half times more likely to have limitations of PADLs compared to their counterparts in rural residence. Conclusion: Limitations of PADLs was significantly associated with age $\geq 75$ years and urban residence. The most significant predictor of limitations of PADLs was urban residence. Measures targeted at these variables and widespread clinic, public health and diverse health promotion strategies to improve PADLs should constitute targets for intervention.
\end{abstract}

Keywords: Geriatrics, Limitations of PADLs, MSDs, Nigeria, Predictors, Primary Care

\section{Introduction}

Aging as a socio-biological process is a natural phenomenon.[1,2] Aging can be 'usual' aging which involves changes due to the aging process as well as the effects of diseases, environmental and host factors such as unhealthy lifestyle and environment or 'successful' aging which refers to the aging process generally unaffected by diseases, environmental factors or lifestyle.[2,3] The geriatric populations are therefore challenged by biological and physiological changes in their musculoskeletal system that impact on their activities of daily living (ADLS) resulting from progressive decline in balance, kinetics and decrease in muscle mass and bone mass.[1,4] The 
musculoskeletal dysfunctions are more pronounced in geriatric population who do not age successfully.[1,3,4] Aging whether active and successful is associated with continuing involvement in physical activities of daily living.[2,5]

Musculoskeletal disorders (MSDs) are major cause of morbidity globally [6-9] with disproportionate occurrence among geriatric population in developing countries such as Nigeria.[9,10] As the world population ages, the geriatric population constitutes an important and integral part of the general population and MSDs will probably increase with its clinical and public health management challenges especially in resource-poor populations.[6-8] Musculoskeletal disorders have been reported as common geriatric morbidities in Ibadan, Nigeria, [9,11] Botswana [12] and in other parts of the world such as India. [8,13] The prevalence of MSDs of $26.8 \%$ was reported in primary care setting in Ibadan, Western, Nigeria,[4] 6.7\% was reported in Idikan community in Ibadan, Nigeria, [11] 38.3\% was reported in a rural community in India [8] and $48.8 \%$ was reported among elderly population in India.[13]

World Health Organization (WHO) has described physical inactivity as the fourth leading risk factor for global mortality with physical inactivity accounting for $30 \%$ of ischaemic heart disease burden, $27 \%$ of diabetes mellitus and $21-25 \%$ of colon and breast cancers.[14] Biophysiologically, the human body is designed to move, thus being physical active can offer a range of musculoskeletal and other diverse benefits. Physical activity of daily living therefore should be part of everyone's daily routine activities and is now more important than ever in health promotion, risk reduction and health maintenance. Physical activity is therefore not an activity that anyone outgrows as there is physical activity for everyone. [15] Although aging is associated with progressive decline in the structural and functional capacity of the musculoskeletal system, one of the principal concerns is the degree of PADLs. $[13,16]$ The degree of PADLs is influenced by multiple factors. [3,17-19] Some of these factors are predisposing factors including demographic geography such as the age, residence, etc; existing medical conditions like MSDs and enabling factors such as social insurance among others. [3,17-19] The major physical activities profiles that have been identified by WHO that make an individual physically active included transport-time, work-time, domestic-time and leisure-time related physical activities.[20]

Physical activities of daily living is therefore one of the greatest challenges of geriatric patients with MSDs and refers to the activities that elderly persons normally do with focus on performance of self-care and societal daily activities.[13,21-23] Several methods of evaluation of activities of daily living(ADL) such as Katz ADL scale(Basic ADL), [5] Lawton-Brody instrumental ADL,[5,21] Global Assessment of Functioning(GAF), [5] modified Global Assessment of Functioning(mGAF-R),[5] Western Ontario and McMaster Universities Osteoarthritis Index(WOMAC) [24] and Community-Oriented Program for control of Rheumatic Diseases(COPCORD) [25] among others have been described. More so, numerous ADL indices at the point of care such as Barthex index have been described.[5] Furthermore, Global Physical Activity Questionnaire[26] and International Physical Activity Questionnaire [27] have been developed. However, there is no universally accepted ADL scale or index or PADLs instrument that is applicable across all musculoskeletal disorders or specific to geriatric population in all sociocultural environments. What constitutes a particular ADLs or PADLs in a specific environment for a particular population may vary. [4,13,28,29] These variations depend on socio-cultural and technological factors. In view of these socio-cultural and technological diversities, researches done on limitations of PADLs among geriatric population with MSDs in a particular environment cannot be generalized beyond the cultural boundaries of that society. A research tailored to the socio-cultural context of Nigerian nation is therefore needed particularly in primary care environment.

In Nigeria, limitations of PADLs among geriatric patients with MSDs assume a relatively low priority and no data exists on their evaluation in primary care settings. Musculoskeletal disorders in geriatric patients lead to varying degrees of limitations of PADLs. [13,18,19,23,.29] This study is therefore anticipated to provoke inquiry by health providers and managers on the limitations of PADLs among geriatric Nigerians with MSDs. It is against this background that the authors were motivated to study the predictors of limitations of physical activities of daily living among geriatric Nigerians with musculoskeletal disorders in under-resourced environment of a primary care clinic of a tertiary hospital in Eastern Nigeria.

\section{Materials and Methods}

\subsection{Study Design}

This was a clinic-based cross sectional study carried out on 130 geriatric Nigerians from August 2012 to December 2012 at the department of Family Medicine of Federal Medical Centre, Umuahia, a tertiary hospital in Umuahia, Abia state, Eastern, Nigeria.

\subsection{Study Setting}

Umuahia is the capital of Abia state, South-east Nigeria. The State is endowed with abundant mineral and agricultural resources with supply of professional, skilled, semi-skilled and unskilled manpower. Economic and social activities are low compared to industrial and commercial cities such as Onitsha, Port Harcourt and Lagos in Nigeria. Until recently, the capital city and its environ have witnessed an upsurge in the number of banks, hotels, schools, markets, industries, junk food restaurants in addition to the changing technological, dietary and social lifestyles.

Federal Medical Centre, Umuahia is located in the 
metropolitan city of Umuahia. It is a tertiary hospital established with the tripartite mandate of service delivery, training and research and serves as a referral centre for primary and secondary public health institutions as well as missionary and private hospitals in Abia state and neighbouring States of Imo, Ebonyi, Rivers and Akwa Ibom states of Nigeria. The department of Family Medicine serves as a primary care clinic within the tertiary hospital setting of the Medical Centre. All adult patients excluding those who need emergency health care services, paediatric patients and antenatal women are first seen at the department of Family Medicine where diagnoses are made. Patients who need primary care are managed and followed up in the clinic while those who need other specialists care are referred to the respective core specialist clinics for further management. The clinic is run by Consultant Family Physicians and postgraduate resident doctors in Family Medicine.

\subsection{Inclusion and Exclusion Criteria}

The inclusion criteria were patients with musculoskeletal disorders aged $\geq 60$ years who gave informed consent for the study. The exclusion criterion included critically ill patients. The eligible patients were consecutively recruited for the study.

\subsection{Sample Size Determination}

The sample size $(\mathrm{N})$ was calculated using the formula [30] $\mathrm{N}=[(\mathrm{Z} \alpha+\mathrm{Z} \beta) \times 2 \mathrm{pq}] / \mathrm{d}^{2}$ Where $\mathrm{N}=$ Desired sample size, $Z=$ The standard normal deviate set at 1.96 which correspond to $95 \%$ confidence level $\mathrm{P}=$ Prevalence of the musculoskeletal disorders, $\mathrm{q}=1.0-\mathrm{p}$, and $\mathrm{d}=$ degree of precision desired set at 0.05 The level of significance was set at $5 \%(\alpha=0.05)$ while the power of the study $(1-\beta)$ was set at $80 \%$. A prevalence of $26.8 \%$ was used based on previous study in Ibadan, Nigeria. [9] $\mathrm{N}=[(1.96 \times 0.05+1.96 \times 0.20) \times 2 \times 0.268 \times 0.732] / 0.05^{2} \mathrm{~N}=76$

The calculated minimum sample size was 76 . However, to improve the precision of the study, the estimated sample size $=\mathrm{Ns}$ was determined considering an anticipated response rate of $90 \%(0.9)$. The estimated sample size (Ns) was determined by dividing the original calculated sample size $(\mathrm{N})$ by the anticipated response rate [31] as follows, $\mathrm{Ns}=\mathrm{N} / 0.9$, where $\mathrm{N}=$ Minimum calculated sample size, $\mathrm{Ns}=$ Selected sample size, anticipated response rate $=0.9$. Thus, the estimated sample size $=76 / 0.9=84$. However, a sample size of 130 patients was used based the time frame for the study.

\subsection{Diagnostic Procedures}

Diagnosis of MSDs was based on standard case definition used in primary care. ${ }^{[10,20,24]}$ It is based on clinical method of medical clerkship: subjective complaints, objective findings and/or primary laboratory and radiological investigations.

\subsection{Diagnostic Criteria for Musculoskeletal Disorders}

Musculoskeletal disorders refer to the disorder of the muscles and skeletal system such as bones and joints.[4,13,17] The commonly affected sites include the spine, lower extremities (hip, knee, ankle, feet, toes) and upper extremities (shoulder, elbow, wrists, hands, fingers). The common musculoskeletal disorders in the primary care clinic were defined as follows:[13,23,32-34]

Chronic low back pain: Patient gave complaints of pain of more than six months duration localized to the lower back (lumbosacral region) with no history of trauma.

Osteoarthritis of weight bearing joints: Patient gave complaints of progressive pain, stiffness and limitation of function in weight bearing joints such as hips and knees; without history of trauma; with or without radiological evidence of osteophytosis or bone sclerosis.

Post traumatic musculoskeletal conditions: Patient gave complaints of pain, swelling of muscles, bones or joints with antecedent history of accident and injuries.

Rheumatoid arthritis: Patient gave complaints of morning stiffness, symmetrical pain and swelling in and around smaller peripheral joints such as hands, feet and wrist before extending to larger joints resulting eventually in varying degrees of deformity and associated muscle wasting with or without positive rheumatoid factor or radiological evidence or rheumatoid nodules.

Gout arthritis: Patient gave complaints of pain, swelling of toes especially the big toes with hyperuricaemia.

\subsection{Data Collection Tool and Process}

Data were collected using pretested, structured interviewer-administered questionnaires designed by the authors using information from literature review and previous studies on activities of daily living[4,5,13,26,19,21-23] The questionnaire tool contained information on basic demographic variables such as age, sex, marital status, education, occupation and residence. The domains of ADLs assessed were physical ADLs. The PADL item was scored on a four (0-3) points Likert scale ordinal response as follows: no affectation of PADLs (no difficulty) $=0$ point while $1-3$ meant variable degrees of affectation of PADLs ranging from mild affectation of PADLs(some difficulty)=1, moderate affectation of PADLs(much difficulty) $=2$ and severe affectation of PADLs(unable to do $)=3$. Physical activities of daily living were assessed in the previous one month. Operationally, patients who scored 0 have no affectation of PADLs while those who scored 1-3 were variably affected.

Ten adult patients with MSDs were used for the pretesting of the questionnaire in the department of Family Medicine of Federal Medical Centre, Umuahia which lasted for two days. The pretesting was done to assess the applicability of the questionnaire tool internally. All the patients used for the pretesting of the questionnaire instrument gave valid and reliable responses confirming the clarity and applicability of the questionnaire tool and 
questions were interpreted with the same meaning as intended. The questionnaire was administered by the lead author and three postgraduate resident doctors in Family Medicine who were recruited and trained for the study. The questionnaire was administered once to each eligible respondent.

\subsection{Operational Definitions}

The researchers defined geriatric patients as those age 60 years and above.[4,8,9] Old age refers to geriatric patients aged $60-74$ years while advanced old age means geriatric patients aged $\geq 75$ years. Primary care refers to the care provided by physicians specifically trained for comprehensive first contact and continuing care for undifferentiated patients including early detection, management of the patient, health promotion and maintenance. $[4,35]$

Physical ADLs refer to activities that elderly persons normally do and focus on performance of daily self-care activities within the place of residence or outdoor environment. What specifically constitutes particular PADLs in a particular environment for a particular person may vary. The following definitions in Nigerian context are used. Physical activities of daily living refer to ambulation activities such as walking and physical ADLs related to domestic activities such as performance of household chores, transportation-time involving walking or cycling to work, market, religious or social functions within the community and leisure time physical activity such as recreational activities and physical exercise. Physical ADLs are necessary for fundamental functioning and help geriatric population live independently in a society.

\subsection{Ethical Imperatives}

Ethical certificate was obtained from the Ethics Committee of the hospital. Informed consent was also obtained from respondents included in the study.

\subsection{Statistical Analysis}

The results generated were analyzed using software Statistical Package for Social Sciences (SPSS) version 13.0, Microsoft Coperation Inc. Chicago, IL, USA. Data analysis was based on univariate frequency table distribution and bivariate cross tabulations to identify important relationships between variables using Chi-square statistics. Odds ratio(OR) and predictor variable analysis using simple logistic regression at $95 \%$ confidence limit was restricted to the variable measures that were statistically significant at bivariate analysis. A p-value of $<0.05$ was considered statistically significant.

\section{Results}

A total of 894 geriatric patients were seen during the study period. Out of these one hundred and thirty had various types of musculoskeletal disorders giving a prevalence of $14.5 \%$. The age ranged from 60 years to 88 years with mean age of $66 \pm 4.7$ years. There were 52 males and 78 females with male to female ratio of $1: 1.5$. Ninetyseven $(74.6 \%)$ of the study population were widows and widowers, eighty-two (63.1\%) had secondary education and more; and ninety-one $(70.0 \%)$ were engaged in primary occupation and retirees from primary occupation who were also engaged in secondary occupation. [Table1].

Table 1: Basic demographic characteristics of the patients with MSDs

\begin{tabular}{ll}
\hline Parameter & Number(\%) \\
\hline Age(years) & $94(72.3)$ \\
$60-74$ (old age) & $36(27.7)$ \\
$\geq 75$ (advanced old age) & \\
Sex & $52(40.0)$ \\
Male & $78(60.0)$ \\
Female & \\
Marital status & $33(25.4)$ \\
Married & $97(74.6)$ \\
Widowed & \\
Education & $48(36.9)$ \\
Primary \& less & $82(63.1)$ \\
Secondary \& more & \\
Occupation & \\
Retired with no secondary & $39(30.0)$ \\
occupation & Primary occupation and retirees \\
with secondary occupation & $91(70.0)$ \\
Residence & \\
Rural & $56(43.1)$ \\
Urban & $74(56.9)$ \\
\hline
\end{tabular}

One hundred and sixteen $(89.2 \%)$ out of 130 patients with MSDs had their PADLs affected fourteen (10.8\%) were unaffected. Bivariate analysis of the demographic variables as related to PADLs showed that age $\geq 75$ years $(p=0.022)$ and urban residence $(p=0.003)$ were statistically significant while other demographic variables were not statistically significant.[Table 2] 
Table 2: Demographic variables as related to physical activity of daily living among the study population

\begin{tabular}{|c|c|c|c|c|c|}
\hline $\begin{array}{l}\text { Demographic } \\
\text { variables }\end{array}$ & \multicolumn{3}{|c|}{ Physical activities of daily living } & $x^{2}$ & P-value \\
\hline & $\begin{array}{l}\text { Affected } \\
\text { Number(\%) }\end{array}$ & $\begin{array}{l}\text { Not affected } \\
\text { Number(\%) }\end{array}$ & $\begin{array}{l}\text { Total } \\
\text { Number(\%) }\end{array}$ & & \\
\hline \multicolumn{6}{|l|}{ Age(years) } \\
\hline $60-74$ & $83(88.3)$ & $11(11.7)$ & $94(100.0)$ & & \\
\hline$\geq 75$ & $33(91.7)$ & $3(8.3)$ & $36(100.0)$ & 4.08 & $0.022 *$ \\
\hline \multicolumn{6}{|l|}{ Sex } \\
\hline Male & $45(86.5)$ & $7(13.5)$ & $52(100.0)$ & & \\
\hline Female & $71(91.0)$ & $7(9.0)$ & $78(100.0)$ & 2.07 & $0.082 * *$ \\
\hline \multicolumn{6}{|l|}{ Marital status } \\
\hline Married & $23(69.7)$ & $10(30.3)$ & $33(100.0)$ & & \\
\hline Widowed & 93(95.9) & $4(4.1)$ & $97(100.0)$ & 3.98 & $0.095^{* *}$ \\
\hline \multicolumn{6}{|l|}{ Education } \\
\hline Primary and less & $43(89.6)$ & $5(10.4)$ & $48(100.0)$ & & \\
\hline Secondary and more & $73(89.0)$ & $9(11.0)$ & $82(100.0)$ & 3.03 & $0.210^{* *}$ \\
\hline \multicolumn{6}{|l|}{ Occupation } \\
\hline $\begin{array}{l}\text { Retired with no - } \\
\text { secondary occupation }\end{array}$ & $35(89.7)$ & $4(10.3)$ & $39(100.0)$ & & \\
\hline \multicolumn{6}{|c|}{ Primary occupation and- } \\
\hline \multicolumn{5}{|c|}{ Retirees with secondary - } & $0.230^{* *}$ \\
\hline \multicolumn{6}{|l|}{ Residence } \\
\hline Rural & $45(80.4)$ & 11(19.6) & $56(100.0)$ & & \\
\hline Urban & $71(95.9)$ & $3(4.1)$ & $74(100.0)$ & 6.04 & $0.003 *$ \\
\hline
\end{tabular}

Remark: *Significant; **Not significant

However, on simple logistic regression of the significant variables at bivariate cross tabulations, urban residence remained statistically significant. A significantly higher proportion of geriatric patients with MSDs from urban residence $(95.9 \%)$ had limitations of PADLs compared to their counterparts from rural residence $(80.4 \%)[(\mathrm{p}=0.010$, $\mathrm{OR}=2.516(1.34-5.02)]$. The geriatric patients in urban residence were two and half times more likely to have limitations of PADLs compared to rural residence.[Table 3]

Table 3: Predictors of limitations of physical activities of daily living among the study population

\begin{tabular}{lllll}
\hline $\begin{array}{l}\text { Demographic } \\
\text { variables }\end{array}$ & $\begin{array}{l}\boldsymbol{\beta} \text { - } \\
\text { coefficient }\end{array}$ & $\begin{array}{l}\text { Odds } \\
\text { ratio }\end{array}$ & $\begin{array}{l}\text { Confidence } \\
\text { interval }\end{array}$ & P-value \\
\hline $\begin{array}{l}\text { Age } \geq 75 \\
\text { years }\end{array}$ & 0.602 & 1.036 & $0.65-2.43$ & 0.089 \\
$\begin{array}{l}\text { Urban } \\
\text { residence }\end{array}$ & 1.228 & 2.516 & $1.34-5.02$ & 0.010 \\
\hline
\end{tabular}

Reference categories: Old age(60 - 74 years); urban residence.

\section{Discussion}

The prevalence of MSDs of $14.5 \%$ in this study is higher than $6.7 \%$ reported in Idikan community in Ibadan, Nigeria [11] and 6\% reported in a general practice clinic in
Jharkhand State, India.[36] However, the prevalence in this study is lower than $26.8 \%$ reported in a primary care clinic at Ibadan, South-west Nigeria,[9] 38.3\% reported among elderly patients in Maharashtra, India [8] and 48.8\% reported among retired elderly population in Pimpri-Pune, India.[13] These reports have buttressed the fact that MSDs are issues of serious medical importance in geriatric patients globally [6,7] and presently escalating in Nigeria as an important component of non-communicable diseases burden in the country. $[9,10,11]$ Aging leads to increase risk of musculoskeletal deconditioning due to decrease blood flow to small and end arteries causing the skeletal bone to degenerate, decrease bone mass (osteopenia) and muscle mass(sarcopenia) leading to impair locomotor ability and incorrect bio-mechanics. The magnitude of this burden of MSDs among the elderly patients is clinically relevant and informative especially in an environment where attendance to hospitals depends on the severity of the medical ailment.[37] Given the inadequacy of primary care data on distribution, determinants and deterrents factors on geriatric MSDs in Nigeria, the most effective clinician intervention is early diagnosis and treatment. [37,38] Although the management of MSDs in geriatric patients can be achieved with medications, the ultimate goal in general is primary 
prevention aimed at reducing the risk of early onset. [37] The earlier the primary prevention is started, the more likely it is to be effective. Clinicians should therefore inquire of their elderly patients of symptoms of MSDs and use optimally clinical methods for the diagnosis of musculoskeletal disorders.[38] The finding of this study therefore predicates the urgent need for geriatric musculoskeletal health education, promotion and counselling during clinical encounter with these patients in primary care settings.[39] These primary prevention strategies will improve their quality of life and reduce subsequent morbid demand on the health delivery system as regards expensive surgical interventions and use of orthopaedics prosthetic devices for severe disability from MSDs.

Physical ADL was significantly limited by age. The older elders with advanced old age had more limitations of PADLs compared with their old age elders. This could be attributed to the age-related changes in the musculoskeletal system amidst other constitutional and non-constitutional risk factors. [4,18,19,39,40] The advance old age elders are more likely to have limitations of PADLs especially when their PADLs are undermined by MSDs.[4,40] Apart from the non-modifiable age-related changes in the musculoskeletal system, the modifiable physical inactivity of senescence is contributory.[1-3] Aging is therefore associated with physical inactivity and physical inactivity is on its own a risk factor for chronic medical conditions such as MSDs.[4,41] Although limitations of PADLs could be found in elderly population but it occurs disproportionately higher in advanced old age elders with MSDs.[4,40,42] Aging inadvertently cause deterioration in PADLs and makes the older elders dependent with decline in functional capacity particularly physical activities.[4,40] As the populations of advanced old age elders increase in resource-poor nations such as Nigeria, MSDs is expected to increase with its effects on PADL unless proactive health promotion, risk reduction and health maintenance strategies are embraced early. Despite the age-related anatomic and patho-physiologic predisposition to limitations of PADL due to MSDs, awareness of these subtleties is needed by clinicians in primary care settings and careful attention to this geriatric health problem is of paramount importance and maintaining a high index of suspicion is vital. There is therefore urgent need for early clinical and public health interventions to improve the PADL of advanced old age elders with MSDs in the resource-poor environment of the study area until senescence makes physical activity impossible.

Limitations of physical activities daily living were more on urban geriatric patients with MSDs compared to their rural counterparts in the study area. The finding of this study is similar to reports from Jamaica on predictors of functional capacity in geriatric population.[18,19] This finding has buttressed the report that urban living residential arrangement in the study area is one of the key socio-environmental factors that impact on the PADLs among geriatric population residing in the urban city environment.[4] The implication of this socioenvironmental orientation in a resource-poor Nigeria setting is better imagined than seen particularly in the urban areas where there is high geriatric related road traffic accident and injuries,[43] poor Street and road design and near absence of recreational facilities. The impact of this poor urban regional geography on geriatric PADLs include restrictive work-related, transport related, leisure related and social function related physical activities generally. Urban environment in the study area had direct and indirect effect on the interaction of geriatric population with the environment and is a major constraint to their physical activity amidst MSDs.[4] This study therefore calls for modifications of the urban regional geography, housing conditions and other diverse requirement to promote physical activity among the elderly patients with MSDs. These urban predispositions to physical inactivity therefore compromises their physical activities of daily living and make the affected elderly patients depend on their family members for most of their physical, instrumental and domestic activities of daily living in addition to economic dependency.

The most significant predictor of limitations of PADL was urban residence. This association could be explained by the influence of socio-environment of the urban areas on physical activities.[4] Geriatric patients with MSDs in the urban environment of the study area are less likely to adhere to the prescribed health education on prophylactic or therapeutic health promotional practices such as walking, jogging, cycling amongst others due to unsafe structure of the urban street roads and proneness to home and commercial falls as a result of poor residential and commercial housing and road designs. Of great concern in Nigeria is that physical inactivity in elderly persons is not always perceived as a health risk. [4] The local perception of limitations of PADLs as a feature of senescence is common. To challenge such socio-cultural belief is difficult. However, international organizations like World Health Organization have approached aging as a part of life cycle that should not be left to chance.[6,41] The is not just dependent on socio-environmental factors alone but is mainly related to poor political will and lack of commitment to public health in Nigeria which is a mirror of poor social services, a reflection of poor environmental management and an indicator of lack of awareness and/or knowledge of the importance of physical activity friendly urban geography. It is only by taking cognizance of the urban residential factors limiting PADLs in geriatric patients with MSDs that appropriate government and private authorities and agencies can plan for effective intervention aimed at improving the physical activities of daily living for this special group of elder citizens in urban city environment. This will guide individual, institutional, community and diverse authorities in designing relevant physical activity-oriented messages to promote geriatric health and functionality in the study area. This study 
therefore provides primary care data required for effective planning of physical activities that are tailored to the geriatric musculoskeletal disorders health care services for the rapidly growing population of elder citizens in the study area.

\subsection{Study Implications}

Aging process has been characterized by progressive decline in physical, biological physiological, social and psychological functions of individuals. In natural aging, apart from the constitutional risk factor of age, many of the non-constitutional risk factors for the limitations of PADL are socio-medically related and can be prevented until senescence occurs. As Nigerian population ages, MSDs are expected to increase with its effect on PADLs. Studies have shown that geriatric population bears a significant burden of physical inactivity and MSDs[4,35] and health system globally and international organizations are waking up to the need for geriatric health and wellness. There is also growing evidence that lack of involvement in PADLs may predispose to cardiovascular health problems. The costs of management of cardiovascular health problem is enormous in terms of physicians visits, medications, physical therapies, hospitalizations, rehabilitations, lost wages, family dysfunction and untimely death.

The care of geriatric patients with MSDs therefore should be a major health and social issues in a resourcepoor environment where aging is also associated with disease, poverty and ignorance and limited options for healthy living. Limitations of PADLs in geriatric Nigerians with MSDs therefore poses a major clinical and public health challenges to population in socio-economic and demographic transition where there is lower level of clinical and social geriatric care. The overall implications of this study are to inform the need for geriatric musculoskeletal health promotion and diverse resource requirements.

\subsection{Study Limitations}

The limitations of this study are recognized by the authors. First and foremost, the sample for the study was drawn from Family Medicine clinic of the hospital. Hence, the findings of this study may not be general conclusions regarding geriatric patients with musculoskeletal disorders attending other outpatient clinics of the hospital.

The findings of this study is not a general conclusion regarding some aspects of physical activities of daily living such as religious activities due to religious and sociocultural diversities in the country; for example among the Nigerians Muslims activities of daily living could involve a lot of squatting, sitting on the floor cross-legged for meals or religious rites. These socio-religious disposition can cause more limitations of PADLs in case of involvement of lower extremities when compared with what is obtained among the Eastern Nigerians of Ibo and Christian extraction with Western socio-cultural customs and religious practices.

This study was designed to describe the physical activities of daily living in relation to musculoskeletal disorders rather than association with specific musculoskeletal disorder or demographic geography or other ADLs. Musculoskeletal disorder is a vast medical problem. However, operational definitions of common musculoskeletal disorder in the primary care clinic in the study area are provided. Thus extrapolation of the findings to specific musculoskeletal disorder should be done with caution. Furthermore, the limitations imposed by the selfreported measure of PADLs among the respondents are recognized by the researcher and since some respondents couldn't clinically and socially give acceptable and true responses in questions related to health practices and lifestyle. In addition, the sample size for the study was relatively small, but this was the number of patients seen within the proposed duration of the study. More so, this study was not on degree of affectation of the physical activities of daily living as regards the scoring system because of the clinical relevance of mild(some difficulty), moderate(much difficulty) and severe affectation(unable to do) of the physical activities of daily living in relation to MSDs.

\section{Conclusion}

Limitations of physical activities of daily living were significantly associated with age $\geq 75$ years and urban residence. The most significant predictor of limitations of physical activities of daily living was urban residence. Measures targeted at these variables and widespread clinic, public health and diverse health promotion strategies to improve physical activities of daily living should constitute targets for intervention in the primary care in underresourced environment.

\section{References}

[1] Mobbs C. Biology of aging. In: Beers MH, Berkow R editors. The Merck Manual of Geriatrics, $3^{\text {rd }}$ ed. New Jersey(USA) Merck and Co Inc White house station 2001: p. 25.

[2] Abanobi OC. Active theory of aging. Core Concepts in Epidemiology \& Public Health Practice. A Quick Reference Manual Owerri, Opinion Research Communications Inc 2010; p.4.

[3] Abanobi OC. Health: Wellness and illness states. Biological, Social, Cultural, Environmental, Nutritional, Behavioural and Health System Factors. Owerri, Opinion Research Communications Inc 2005; p. 57-65.

[4] Iloh GUP, Chuku A, Dike OJ, Amafili OP, Nnaji BC. Burden of Limitations of Activities of Daily Living Among Geriatric Nigerians with Musculoskeletal Disorders in a Resource-Limited Nigerian Primary Care Clinic in Eastern Nigeria. American Journal of Health Research. 2013; 1: 916. 
[5] 'Activities of Daily Living Evaluation' Encyclopedia of Nursing \& Allied Health. Ed. Kristine Krapp. Vol 1. Gale Cengage, 2002. eNotes.com. 19 Aug, 2012 $<$ http://www.enotes.com/activities_daily_living_evaluation_ reference/>

[6] WHO. The burden of musculoskeletal conditions at the start of the new millennium. World Health Organization Technical Report Series. Report of a WHO Scientific Group, Geneva. WHO 2003 p. 218.

[7] Tsou IY, Ching HH. The bone and joint decade 2000-2010 for prevention and treatment of musculoskeletal disease. Ann Acad Med Singapore 2002; 31: 69-70.

[8] Agrawal S, Deo J, Verma AK, Kotwal A. Geriatric health: Need to make it an essential element of primary health care. India J Public Health 2011; 55: 25 - 9.

[9] Adebusoye LA, Ladipo MM, Owoaje ET, Ogunbode AM. Morbidity pattern amongst elderly patients presenting at a primary care clinic in Nigeria. Afr J Prm Health Care Fam Med 2011; 3(1), Art $\neq 211$.

[10] Abdulraheem IS, Abdulrahman AG. Morbidity pattern among the elderly population in a Nigerian tertiary health care institution: analysis of a retrospective study. Niger Med Pract 2008; 54: 32-8.

[11] Ogunniyi A, Baiyewu O, Gureje O. Morbidity pattern in a sample of elderly Nigerians resident in Idikan community, Ibadan. West Afr J Med 2001; 20: 227 - 31 .

[12] Clausen F, Sandberg E, Ingstaad B, Hjortdan P. Morbidity and healthcare utilization among the elderly people in Mmankgodi village. J Epidemiol Community Health 2000; 54: $58-63$.

[13] Benerjee A, Jahdhav SL, Bhawalkar JS. Limitations of activities in patients with musculoskeletal disorders. Ann Med Health Sci Res 2012; 2: 5-9.

[14] World Health Organization. Global strategy on diet, physical activity and health 2004. Available from http://www.who.int/dietphysicalactivity/en/

[15] Centre for Disease Control and Prevention. Physical Activity for everyone 2007. Available from http://www.cdc.gov/nccdphp/dnpa/physical/measuring/exam ples.htm

[16] Joshi K, Kumar R, Avasthi A. Morbidity profile and its relationship with disability ans psychological distress among elderly people in Northern India. Int J Epidemiol 2003; 32: 978-87.

[17] Ettinger W. Aging and osteoarthritis In Beers MH, Berkow $R$ eds. The Merck Manual of Geriatrics, $3^{\text {rd }}$ edn. NJ(USA) Merck \& Co Inc White house station 2001:p. 467-472.

[18] Morris C, Bourne PA, Eldemire-Shearer D, McGrowder DA. Social determinants of physical exercise in older men in Jamaica. N Am J Med Sci 2010; 2: 87-96.

[19] Bourne PA. Activities of daily living, instrumental activities for daily living and predictors of functional capacity of older men in Jamaica. N Am J Med Sci 2009; 1: 184-192.

[20] World Health Organization. Physical activity 2007. Available http://www.who.int/dietphysicalactivity/publications/
[21] Graf C. The Lawton instrumental activities of daily living scale. Am J Nurs 2008; 108: 52 - 62 .

[22] Sadosky AB, Bushmakin AG, Cappelleri JC, Lionberger DR Relationship between patient-reported disease severity in osteoarthritis and self-reported pain, function and work productivity. Arthritis Research \& Therapy 2010; 12: R162.

[23] Iloh GUP, Amadi AN, Awa-Madu J. Common geriatric emergencies in a rural hospital in South-Eastern, Nigeria. Niger J Clin Pract 2012; 15: 333-337.

[24] McConnell S, Kolopack P, Davis AM. The Western Ontario and McMaster Universities Osteoarthritis Index (WOMAC): a review of its utility and measurement properties. Arthritis Rheum 2001; 45: 453 - 61.

[25] Chopra A, Patil J, Billempelly V, Relwani J, Tandale HS. Prevalence of rheumatic diseases in a rural population in western India. A WHO-ILAR COCORD Study. J Assoc Physicians India 2001; 49: 240-46.

[26] World Health Organization. Global Physical Activity Questionnaire 2007. Available from http://www.who.int/chp/steps/resources/GPAQ Analysis G uide.pdf

[27] International Physical Activity Questionnaire. Guidelines for Data Processing and Analysis of the International Physical Activity Questionnaire. Available from http://www.ipaq.ki.se/scoring.pdf

[28] Iloh GUP, Chuku A, Amadi AN. Burden of noncommunicable diseases among geriatric Nigerians in a rural hospital in resource-constrained setting of Eastern Nigeria. Science Journal of Public Health 2013; 1: 141-146.

[29] van Dijk GM, Veenhof C, Lankhorst GJ, Dekker J. Limitations of activities in patients with osteoarthritis of the hip or knee: The relationship with body functions, comorbidity and cognitive functioning. Disabil Rehabil 2009; 31: $1685-91$.

[30] Ibrahim T. Sample size determination. In: Research Methodology and Dissertation writing for Health and Allied Health Professionals. Abuja, Nigeria Cress Global Link Limited; 2009: 70-75.

[31] Araoye MO. Sample size determination. Research Methodology with Statistics for Health and Social Sciences, Ilorin, Nathadex Publishers, 2004. p.115- 21.

[32] Graeme M, Helena B. ICPC-2-E: The Electronic Version ICPC-2. Fam Pract 2000; 17: 448.

[33] Webb CW, O'Connor FG. Low back pain in primary care: An evidence-based approach. In: South-Paul JE, Matheny SC, Lewis EL editors. Current Medical Diagnosis and Treatment in Family Medicine, $3^{\text {rd }}$ edition, New York. Lange Medical Books 2011. p. 257 - 265.

[34] Woolf AD, Pfleger B. Burden of major musculoskeletal conditions. Bull World Health Organ 2003; 81: 646 - 656.

[35] Iloh GUP, Ikwudinma AO, Obiegbu NP. Obesity and Its Cardio-metabolic Co-morbidities Among Adult Nigerians in a Primary Care Clinic of a Tertiary Hospital in SouthEastern Nigeria. J Fam Med Primary Care 2013; 2: 20-26.

[36] Mukhopadhyay K, Singh R. Common Geriatric Cases Seen by a General Practitioner in an Urban Area of Jharkhand 
State, India. J Fam Med Primary Care 2012;1: 164 - 5.

[37] Iyaniwura CA. Health promotion in general medical practice in Osun state. Niger Med Pract 2004; 45: 29 - 32.

[38] Akesson K, Dreinofer KE, Woolf AD. Improved education in musculoskeletal conditions is necessary for all doctors. Bull World Health Organ 2003; 81: 677 - 83.

[39] Leveille SG. Musculoskeletal aging. Curr Opin Rheumatol 2004; 16: $114-8$.

[40] Gregg EW, Cauley JA, Stone K, Thompson TJ, Bauer DC, Cummings SR, et al. The Study of Osteoporotic Fractures
Resaearch Group: Relationship of changes in physical activity and mortality among older women. JAMA 2003; 289: $2379-86$.

[41] WHO. The Global Embrace, Aging and life course. In: The Global Embrace Handbook. Geneva. World Health Organization 2001.

[42] Brooks PM. The burden of musculoskeletal disease-a global perspective. Clin Rheumatol 2006; 25: 778 - 81 .

[43] Aguocha UB, Njoku PU, Ofia M, Echem RC. Orthopaedic injuries in the elderly: Federal Medical Centre, Umuahia experience. PortHarcourt Med J 2010; 5: 77-86. 